phương pháp là $62,1 \%$ và $56,1 \%{ }^{8}$ Tuy nhiên, trong nghiên cứu chúng tôi chỉ ghi nhận chỉ có 4/30 bệnh nhân có giãn khoảng gian bào.

Trung vị giá trị MA tại vị trí $5 \mathrm{~cm}$ và $15 \mathrm{~cm}$ trên đường $Z$ cao hơn ở nhóm VTQTN so với nhóm không VTQTN trên nội soi, tuy nhiên sự khác biệt có ý nghĩa thống kê. Các nghiên cứu trước đầy đã chỉ ra rằng giá trị MA cao hơn ở các bệnh nhân có VTQTN so với nhóm trào ngược không có VTQTN và cao hơn nhóm chứng khỏe manh. ${ }^{4} \mathrm{Nghiên}$ cứu của Matsumura cho thấy đo TCM có giá trị chẩn đoán phân biệt GERD và nóng rát chức năng tương tự như khi sử dụng phương pháp đo pH trở kháng 24 giờ. ${ }^{4}$

Điểm hạn chế trong nghiên cứu của chúng tôi đó là cõ mẫu còn nhỏ, chưa đối chiếu được với tiêu chuẩn vàng là đo $\mathrm{pH}$-trở kháng thực quản 24 giờ cũng như không thu tuyển được nhóm bệnh nhân viêm thực quản trên nội soi mức độ nặng Los Angeles từ độ $C$ trở lên để so sánh. Đây là nghiên cứu bước đầu do vậy giá trị của kĩ thuật TCM và $\mathrm{MBH}$ trong chẩn đoán GERD cần được đánh giá thêm trong các nghiên cứu tương lai với cõ̃ mẫu lớn hơn và có tiêu chuẩn vàng đối chiếu.

\section{KẾT LUẬN}

Nghiên cứu chúng tôi không ghi nhận sự khác biệt về các đặc điểm trên mô bênh học và đo điện thế niêm mạc thực quản giữa nhóm có và không có viêm thực quản trên nội soi, cũng như không có sự khác biệt về giá trị điện thế niêm mạc thực quản giữa nhóm có và khổng có viêm thực quản trên mô bênh học.

Lời cảm ơn. Nghiên cứu nằm trong đề tài cấp nhà nước của Bộ Khoa học và Công nghệ "Nghiên cứu đánh giá rối loạn vận động và bài tiết một số bệnh lý dạ dày, thực quản" mã số ĐTĐLCN.04/20.

\section{TÀI LIÊU THAM KHẢO}

1. Vakil N, van Zanten SV, Kahrilas P, Dent J, Jones R. The Montreal definition and classification of gastroesophageal reflux disease: a global evidence-based consensus. The American journal of gastroenterology. 2006;101(8):1900-1920; quiz 1943.

2. Gyawali CP, Kahrilas PJ, Savarino E, et al. Modern diagnosis of GERD: the Lyon Consensus. Gut. 2018;67(7):1351-1362.

3. Fiocca $R$, Mastracci $L$, Riddell $R$, et al. Development of consensus guidelines for the histologic recognition of microscopic esophagitis in patients with gastroesophageal reflux disease: the Esohisto project. Human pathology. 2010; 41(2): 223-231.

4. Matsumura $T$, Ishigami $H$, Fujie $M$, et al. Endoscopic-Guided Measurement of Mucosal Admittance can Discriminate Gastroesophageal Reflux Disease from Functional Heartburn. Clin Transl Gastroenterol. 2017;8(6):e94.

5. Farre $R$, Blondeau $K$, Clement $D$, et al. Evaluation of oesophageal mucosa integrity by the intraluminal impedance technique. Gut. 2011;60(7):885-892.

6. Kessing BF, Bredenoord AJ, Weijenborg PW, Hemmink GJ, Loots CM, Smout AJ. Esophageal acid exposure decreases intraluminal baseline impedance levels. Am J Gastroenterol. 2011;106(12):2093-2097.

7. Ismail-Beigi F, Horton PF, Pope CE, 2nd. Histological consequences of gastroesophageal reflux in man. Gastroenterology. 1970;58(2):163-174.

8. Zhou LY, Wang Y, Lu JJ, et al. Accuracy of diagnosing gastroesophageal reflux disease by GerdQ, esophageal impedance monitoring and histology. J Dig Dis. 2014;15(5):230-238.

\title{
NGHIÊN CỨU GIÁ TRI THANG ĐIỂM VIÊM PHỔI SEOUL TRÊN BÊ̂NH NHÂN VIÊM PHỔI THỨ PHÁT SAU ĐộT QUỴ NÃO CẤP TẠI TRUNG TÂM ĐộT QUỴ PHÚ THọ
}

\section{TÓM TẮT}

Mục tiêu: Khảo sát giá trị thang điểm Viêm phổi Soeul ở bệnh nhân đột quy não trong giai đoạn cấp. Đối tượng và phương pháp nghiên cứu: Gồm 65 bệnh nhân đột quỵ não lần đâu được nhập viện điều

*Sở Y tế Phú Tho

**Bênh viện Đa khoa tỉnh Phú Tho

Chịu trách nhiệm chính: Nguyễn Huy Ngọc

Email: ngohuynguyen8888@gmail.com

Ngày nhận bài: 7.4.2021

Ngày phản biện khoa học: 26.5.2021

Ngày duyệt bài: 8.6 .2021

\section{Nguyễn Huy Ngọc*, Nguyễn Quang Ân**}

trị nội trú tại Trung tâm Đột quy - Bênh viện tỉnh Phú Tho từ tháng 11 năm 2020 đến tháng 3 năm 2021. Chẩn đoán viêm phổi bênh viên theo Hướng dẫn chẩn đoán và điều trị bệnh hô hấp do Bộ $Y$ Tế ban hành năm 2012. Nghiên cứu được tiến hà̀nh theo phương pháp tiến cứu, thống kê mồ tả. Kết quả: Tuổi trung bình là $62,0 \pm 11,5$, tỉ lê nam/ nữ: $2 / 1$, điểm NIHSS trung bình $8,2 \pm 6,5$ và bệnh nhân có thông khí cơ hoc chiếm 7,3\%. Tí lê viêm phổi bênh viện là 13,5\%. Ở bệnh nhân ở thể đột quy chảy máu, có thông khí cơ học, tình trạng rối loạn ý thức nặng (Glasgow < 9), mức độ đột quy nặng (NIHSS $\geq 15$ ) thì có tỉ lệ viêm phổi cao hớn hẳn với $\mathrm{p}<0,001$; không có mối liên quan giữa tuổi, giới và mức huyết áp với tỉ lệ viêm 
phổi bệnh viện ở bệnh nhân đột quy. não. Tỷ lệ bị viêm phổi thấp nhất ở những bênh nhân có điểm Viêm phổi Seoul (VPS) $=0(0 \%)$, tỷ lệ viêm phổi cao nhất là ở những bệnh nhân có điểm Viểm phổi Seoul (VPS) = 5 (83,33\%). Kết luân: Ở bệnh nhân đột quy não giai đoạn cấp, viêm phối bệnh viện chiếm 13,5\%. Có mối liên quan giữa đột quỵ não thể chảy máu, có thông khí cơ hoc, tình trang rối loan ý thức năng, mức độ đột quy nặng với tỉ lệ viêm phổi bệnh viện.Thang điểm VPS có khả năng dự báo viêm phổi với độ đặc hiệu cao nhưng độ nhạy thấp.

Tư khóa: Đột quỵ não, viêm phổi bệnh viện, thang điểm VPS.

\section{SUMMARY}

\section{RESEARCH VALUE OF THE SEOUL PNEUMONIA SCALE IN PATIENTS PNEUMONIA SECONDARY TO ACUTE STROKE AT STROKE CENTER PHU THO}

Background: Survey value of Seoul pneumonia score in patients with brain stroke in the acute stage. Subjects and Methods: Including 65 first-time stroke patients admitted to the hospital for inpatient treatment at the Stroke Center - Phu Tho Provincial Hospital from November 2020 to March 2021. Diagnosis of nosocomial pneumonia according to the Guidelines for diagnosis and treatment of respiratory diseases issued by the Ministry of Health in 2012. Research was conducted according to the method of prospective, descriptive statistics. Results: Average age is $62,0 \pm 11,5$, male/female ratio: $2 / 1$, average NIHSS score $8,2 \pm 6,5$ and patients with mechanical ventilation 7,3\%. Nosocomial pneumonia ratio 13,5\%. In patients with hemorrhagic stroke, with mechanical ventilation, Severe disorders of consciousness (Glasgow < 9), moderate to severe stroke (NIHSS $\geq$ 15) had a much higher rate of pneumonia with $p<$ 0,001 ; There was no relationship between age, sex and blood pressure level with the incidence of nosocomial pneumonia in stroke patients. The rate of pneumonia was lowest in patients with a score of Seoul pneumonia (VPS) $=0(0 \%)$, The rate of pneumonia was highest in patients with a score of Seoul pneumonia (VPS) $=5(83,33 \%)$. Conclusion: In patients with acute stroke, nosocomial pneumonia take $13.5 \%$. There is an association between hemorrhagic stroke, mechanical ventilation, Severe disorders of consciousness, moderate to severe stroke and the rate of nosocomial pneumonia. VPS score has the ability to predict pneumonia with high specificity but low sensitivity. scale.

Key words: stroke, nosocomial pneumonia, VPS

\section{I. ĐĂT VẤN ĐỀ}

Đột quy não có rất nhiều biến chứng, trong đó nguy hiểm và hay gặp nhất đó là Viêm phổi bênh viện. Biến chứng này thường xảy ra trong tuần đầu điều trị, đăc biệt là ba ngày đầu sau khởi phát đột quy. Viêm phổi bệnh viện sau đột quy chiếm một tỳ lệ khá cao, có thể lên tới $50 \%$ [1]. Xác định bệnh nhân có nguy cơ cao mắc viêm phổi trong giai đoạn đột quy não cấp tính là vô cùng cân thiết, góp phần nâng cao chất lượng điều trị bệnh nhân đột quỵ. não. Thang điểm Viêm phổi Seoul rất có giá trị trong việc sàng lọc những đối tượng có nguy cơ cao với những tiêu chí đơn giản, dễ áp dụng dụng cho bệnh nhân đột quỵ não trong giai đoạn cấp [2]. Trên thế giới tai các Trung tâm đột quy đã có rất nhiều nghiên cứu ứng dụng thang điểm Viêm phổi Seoul, nhưng ở Việt Nam thì chưa có nhiều nghiên cứu về thang điểm này nên chúng tôi tiến hành nghiên cứu với mục tiêu: Xác định giá trị thang điểm Viêm phổi Soeul trên bệnh nhân viêm phổi thứ phát sau đột quy não cấp.

\section{II. ĐỐI TƯƠNGG VÀ PHƯƠNG PHÁP NGHIÊN CỨU}

2.1. Đối tương nghiên cứu: Gồm 65 bệnh nhân đột quy nã̃o được nhâp viên điều trị nội trú tại Trung tâm Đột quy. - Bệnh viện tỉnh Phú Thọ từ tháng 11 năm 2020 đến tháng 3 năm 2021.

Tiêu chuẩn chôn bênh nhân: Bệnh nhân mắc đột quy não được chẩn đoán dựa vào định nghĩa đột quỵ não của Tổ chức y tế thế giới và hình ảnh chup CT-scann so não; Đột quy não lần đầu; bệnh nhân đồng ý tham gia nghiên cứu. Tiêu chuẩn xác định bệnh nhân viêm phổi bênh viện sau đột quy: Áp dụng tiêu chuẩn chẩn đoán viểm phổi bệnh viện theo Hướng dẫn chẩn đoán và điều trị bệnh hô hấp do Bộ Y Tế ban hành năm 2012, theo quyết định số 4235/QĐ-BYT [3].

Tiêu chuẩn loại trừ: Đột quỵ não tái diễn; bệnh nhân tử vong hoặc xin về trong vòng 48 giờ sau nhập viện; viêm phổi cộng đồng; tổn thương não không phải đột quỵ; lao phổi, u phổi; bệnh nhân can thiệp ngoại khoa; không đồng ý tham gia nghiên cứu.

2.2. Phương pháp nghiên cứu: tiến cứu; kết hợp thống kê mô tả và phân tích.

Nội dung nghiên cứu: thu thâp thông tin đặc điểm dịch tể bệnh nhân, đặc điểm lâm sàng, cận lâm sàng, xác định tỷ lệ viểm phổi bệnh viện sau đột quy não, phân tích yếu tố nguy cơ viêm phổi theo các chỉ tiêu về bệnh nhân đột quy não khi mới nhập viện, xác định điểm số Viêm phổi Seoul, tính phần trăm dự báo viêm phổi theo từng điểm số.

Xử lý số liệu: Các phân tích thống kê được xử lý bằng phần mềm SPSS 20.0 (Statistical Package for Social Science 20.0).

\section{KẾT QUẢ NGHIÊN CỨU}

Bảng 1. Một số đặc điểm chung

\begin{tabular}{|c|c|c|}
\hline \multicolumn{2}{|c|}{ Đặc điếm } & $\mathrm{N}=65$ \\
\hline \multirow{2}{*}{ Tuổi } & $(\mathrm{X} \pm \mathrm{SD})$ & $62,0 \pm 11,5$ \\
\cline { 2 - 3 } & $<50$ & $8(12,3 \%)$ \\
\hline
\end{tabular}


TẠP CHÍ Y HỌC VIẸT NAM TẠP 503 - THÁNG 6 - SỐ 2 - 2021

\begin{tabular}{|c|c|c|}
\hline \multirow{2}{*}{} & $50-69$ & $28(43,0 \%)$ \\
\cline { 2 - 3 } & $\geq 70$ & $29(44,6 \%)$ \\
\hline \multirow{3}{*}{$\begin{array}{c}\text { Giới (nam/nữ }) \\
\text { Glasgow }\end{array}$} & $(\mathrm{X} \pm \mathrm{SD})$ & $2 / 1$ \\
\cline { 2 - 3 } & 15 điếm & $12,0 \pm 2,6$ \\
\cline { 2 - 3 } & $9-14$ điếm & $17(26,2 \%)$ \\
\cline { 2 - 3 } & $3-8$ điếm & $3(4,6 \%)$ \\
\hline \multirow{4}{*}{$\begin{array}{c}\text { Diểm } \\
\text { NIHSS }\end{array}$} & $(\mathrm{X} \pm \mathrm{SD})$ & $8,6 \pm 6,5$ \\
\cline { 2 - 3 } & $0-4$ & $26(40,0 \%)$ \\
\cline { 2 - 3 } & $5-15$ & $28(43,1 \%)$ \\
\cline { 2 - 3 } & $16-20$ & $5(7,6 \%)$ \\
\cline { 2 - 3 } & $21-42$ & $6(9,2 \%)$ \\
\hline \multicolumn{2}{|c|}{ Thông khí cơ học $(\mathrm{n}, \%)$} & $16(24,6 \%)$ \\
\hline
\end{tabular}

*RLYT: Rối loạn ý thức

Tuổi trung bình của nhóm bệnh nhân nghiên cứu là 62 tuổi, trong đó nhóm tuổi từ 70 trở lên chiếm tỉ lệ cao nhất (44,6\%). Nam cao hơn nữ với tỉ lệ nam/ nữ =2/1. Bệnh nhân với biểu hiện rối loạn ý thức chiếm 30,8\%, trong đó RLYT nặng chiếm 4,6\%. Điểm NIHSS 5-15 chiếm tỉ lệ cao nhất (43,1\%), nhóm bệnh nhân nghiên cứu có điểm NIHSS $\leq 15$ là chủ yếu với $83,1 \%$. Trong số 65 bệnh nhân có 16 (24,6\%) ca có thông khí nhân tạo ở các hình thức khác nhau.

Bảng 2. Môi liên quan giữa viêm phổi và một số yêu tố dịch tễ nhóm bệnh nhân nghiên cứu

\begin{tabular}{|c|c|c|c|c|}
\hline & $\begin{array}{l}\text { Mắc VP } \\
(n=19)\end{array}$ & $\begin{array}{l}\text { Không } \\
\text { mắc VP } \\
(n=46)\end{array}$ & $\mathrm{p}$ \\
\hline \multirow{2}{*}{$\begin{array}{c}\text { Thông khí } \\
\text { cơ học }\end{array}$} & Có & $55,6 \%$ & $44,4 \%$ & \multirow{2}{*}{0,001} \\
\hline & Không & $19,2 \%$ & $80,8 \%$ & \\
\hline \multirow{2}{*}{$\begin{array}{l}\text { Rối loạn ý } \\
\text { thức (Điếm } \\
\text { Glasgow) }\end{array}$} & $<9$ & $94,8 \%$ & $5,2 \%$ & \multirow[b]{2}{*}{0,001} \\
\hline & $\geq 9$ & $19,4 \%$ & $80,6 \%$ & \\
\hline \multirow{2}{*}{$\begin{array}{l}\text { Mức độ đột } \\
\text { quy (Điểm } \\
\text { NIHSS) }\end{array}$} & $<15$ & $10,8 \%$ & $89,2 \%$ & \multirow[b]{2}{*}{0,001} \\
\hline & $\geq 15$ & $72,5 \%$ & $27,5 \%$ & \\
\hline \multicolumn{2}{|c|}{ Có rối loạn nuốt } & $95,6 \%$ & $4,3 \%$ & 0,001 \\
\hline
\end{tabular}

Qua bảng trên cho thấy ở bệnh nhân có thông khí cơ học, tình trạng rối loạn ý thức nặng (Glasgow < 9), mức độ đột quy nặng (NIHSS 15) thì có tỉ lệ viêm phổi cao hơn rõ ràng. Những bệnh nhân có thông khí cơ học tỉ lệ viêm phổi cũ̃ng cao hơn không có thông khí cơ học. Sự khác biệt rất có ý nghĩa thống kê với $\mathrm{p}<0,001$.

Bảng 3.3: Tỷ lệ viêm phổi bệnh viện ở nhóm bệnh nhân nghiên cứu theo VPS (viêm phối Seoul)

\begin{tabular}{|c|c|c|c|c|}
\hline $\begin{array}{c}\text { Điếm } \\
\text { VPS }\end{array}$ & $\begin{array}{c}\text { Số } \\
\text { lượng }\end{array}$ & VP & KVP & $\begin{array}{c}\text { Tỷ lệ viêm } \\
\text { phổi }\end{array}$ \\
\hline 0 điếm & 1 & 0 & 1 & $0 \%$ \\
\hline 1 điếm & 15 & 1 & 14 & $6,6 \%$ \\
\hline 2 điếm & 13 & 2 & 13 & $15,3 \%$ \\
\hline
\end{tabular}

\begin{tabular}{|c|c|c|c|c|}
\hline 3 điểm & 12 & 3 & 7 & $25,0 \%$ \\
\hline 4 điểm & 15 & 5 & 10 & $33,33 \%$ \\
\hline 5 điểm & 9 & 8 & 1 & $88,8 \%$ \\
\hline Tống & $\mathbf{6 5}$ & $\mathbf{1 9}$ & $\mathbf{4 6}$ & \\
\hline
\end{tabular}

Bệnh nhân đột quy não có điểm viêm phổi Seoul càng cao thì tỷ lệ bị viêm phổi bệnh viện càng cao. Tỷ lệ bị viêm phổi thấp nhất ở những bệnh nhân có điểm VPS = 0 (tỷ lệ bị viêm phổi là $0 \%$ ), tỷ lệ viêm phổi cao nhất là ở những bệnh nhân có điểm VPS $=5$ (tỷ lệ viêm phổi là $88,8 \%)$. Như vậy điểm VPS càng cao thì tỉ lệ bị viêm phổi càng cao.

\section{BÀN LUÂNN}

4.1. Một số đặc điểm chung của nhóm bệnh nhân nghiến cứu. Tuổi trung bình ở nhóm bệnh nhân nghiên cứu là 66 , trong đó nhóm 60 tuổi trở lên là chủ yếu với $67,0 \%$. Kết quả này cũng phù hợp với các thống kê trong và ngoài nước trước đây đều khẳng định đột quy. xảy ra chủ yếu ở những bệnh nhân cao tuổi và tuổi cao là một yếu tố rõ ràng của đột quy. não dù những năm gần đây đột quy não đang có xu hướng trẻ hóa [4]. Kết quả ở nghiên cứu của chúng tôi cũng một lần nữa góp phân khẳng định đột quy. xuất hiện ở nam giới với tỉ lệ cao hơn so với nữ. Kết quả từ 59 nghiên cứu khác nhau ở 19 quốc gia cho thây tỷ lệ nam giới mắc đột quy. não cao hơn nữ giới, tỷ lệ nam/nữ = $1,15: 1$ [5]. Ở nghiên cứu này, có khoảng 2/3 bệnh nhân thuộc nhóm đột quy. nhồi máu $(63,3 \%)$. Tỷ lệ này có thấp hơn so với ở một nghiên cứu đánh giá viêm phổi sau đột quy tại Athen, Hy Lạp với cõ mẫu là 3204 (thì tỷ lệ nhồi máu não $85 \%$ ). Lí giải cho điều này là ở Việt Nam cũng như các nước châu Á, kiểm soát huyết áp thường không đạt mục tiêu nên gây ra đột quy. chảy máu não cao hơn (huyết áp cao là nguyên nhân của chảy máu não) [6].

Nghiên cứu của chúng tôi cho thấy điểm Glasgow trung bình là $14 \pm 2,1$ bệnh nhân có điểm Glasgow từ 3-8 chỉ chiếm 3,7\%. Cũng như các nghiên cứu khác về viêm phổi sau đột quy, những trường hợp điểm Glasgow thấp (tương ứng với tổn thương não nặng) có thể tử vong trong vòng $48 \mathrm{~h}$ và bi loại ra khỏi nghiên cứu, nên bệnh nhân với điểm Glasgow thâp trong nhóm nghiên cứu chỉ chiếm tỉ lệ nhỏ.

4.2. Mối liên quan giữa viêm phổi và một số đặc điểm của nhóm bệnh nhân. Viểm phổi là biến chứng thường gặp và là nguyên nhân chính gây tử vong ở bệnh nhân đột quỵ não. Kết quả nghiên cứu của chúng tôi về tỷ lệ viêm phổi sau đột quỵ não là $13,5 \%$. Tỷ lệ này 
qua các nghiên cứu rất khác nhau tùy theo từng cơ sở điều trị, với cơ sở điều trị chuyên khoa về đột quỵ tỷ lệ này có thể từ 3,9\% đến 44\%.

Phân tích các yếu tố chúng tôi nhận thấy bệnh nhân đột quỵ não mức độ nặng (NIHSS $\geq$ 15), có rối loạn ý thức nhiều (Điểm Glasgow < 9), bệnh nhân đột quỵ não thể chảy máu, có rối loạn nuốt và phải thông khí cơ học thì có tỉ lệ viểm phổi cao hơn hẳn $(\mathrm{p}<0,001)$. Kết quả này cũng giống những nhận xét ở các công trình nghiên cứu trước. Rối loạn nuốt là triệu chứng rất thường gặp trong đôt quy não do ảnh hưởng của tổn thương não dẩn đến suy giảm ý thức, chức năng thần kinh điều khiển động tác nuốt và từ rối loạn nuốt dẫn đến hít phải thức ăn vào đường thở là cơ chế chính của viêm phổi sau đột quy não và nó là một yếu tố nguy cơ cao của viêm phổi sau đột quy não [5]. Yếu tố thông khí cơ học (đặt ống nội khí, mở khí quản - thở máy) là nguy cơ cho viêm phổi ở bệnh nhân đột quy. não đã được khẳng định qua nhiều nghiên cứu. Không chỉ riêng bệnh nhân đột quỵ não, Viêm phổi là một biến chứng ở khoảng $28 \%$ bệnh nhân được thở máy nói chung. Tỉ lệ viêm phổi tăng cùng với thời gian thở máy, tỳ lệ này ước tính là 3,3\% mỗi ngày trong 5 ngày đầu, $2,3 \%$ mỗi ngày cho ngày $6-10$, và $1,3 \%$ mối ngày sau ngày thứ 10 thở máy [6]. Mặc dù ở một số nghiên cứu khác cho thấy tuổi cao, nữ giới và bệnh nhân có cơn tăng huyết áp kịch phát khi vào viện là yếu tố làm tăng tỉ lệ mắc viêm phổi bệnh viện ở bệnh nhân dodotj quỵ não nhưng ở nghiên cứu này, chúng tôi chưa thấy sự khác biệt. Điều này có thể do cõ mẫu nghiển cứu chưa đủ lớn để rút ra kết luận.

4.3 Giá trị của thang điểm Viêm phổi Soeul. Trong nghiên cứu xây dựng thang điểm Viêm phổi Seoul (VPS) năm 2006, thang điểm này dự báo và phân loại nguy cơ viêm phổi sau đột quỵ. não như sau: với 0 điểm VPS nguy cơ viêm phổi là $0 \%$, với 1 điểm VPS nguy cơ viêm phổi là $0,9 \%$, với 2 điểm VPS nguy cơ viêm phổi là $5,3 \%$, với 3 điểm VPS nguy cơ viêm phổi là $38,2 \%$, với 4 điểm VPS nguy cơ viêm phổi là $74,2 \%$, với 5 điểm VPS nguy cơ viêm phổi là $100 \%$ [2]. Trong nghiên cứu của Cugy và Sibon [7] thang điểm VPS đã được áp dụng để kiểm tra khả năng dự đoán nguy cơ viểm phổi, kết quả độ đặc hiệu để phát hiện viêm phổi là 0,907 nhưng độ nhạy lại chỉ có 0,583 . Trong nghiên cứu này, chúng tôi tiến hành khảo sát thang điểm VPS cho các bệnh nhân đột quỵ não, kết quả cho thấy: bênh nhân đột quy não có điểm VPS càng cao thì khả năng bị viêm phổi càng cao. Trong những bệnh nhân có điểm VPS $=0$ thì không có ai bị viêm phổi (nguy cơ bị viêm phổi là $0 \%$ ), nguy cơ viêm phổi cao nhất là ở những bênh nhân có điểm VPS $=5$ (nguy cơ viêm phối là $83,33 \%$ ). Với kết quả trên chúng tôi thấy bệnh nhân có điểm VPS là 0 và 5 thì thang điểm VPS đưa ra dự đoán viêm phổi khá chính xác. Tuy nhiên, với bệnh nhân có điểm VPS là 3 và 4 thì tuy số lượng bệnh nhân nhiều nhưng tỷ lệ viêm phổi thực sự khá thấp, đặc biệt khoảng cách giữa 4 điểm VPS và 5 điểm VPS chênh nhau khá nhiều $(33,33 \%$ và $83,33 \%)$.

Nếu giả thiết những bệnh nhân có điểm VPS từ 0-2 là không có nguy cơ viêm phổi thì chúng tôi thấy trong số 130 bệnh nhân có điểm VPS từ 0-2 chỉ có 6 bệnh nhẩn bị viêm phổi tỷ lệ là $4,6 \%$ còn 124 bềnh nhân là không viêm phổi, đô đặc hiệu xác định không viêm phổi là 95,4\% (124/130). Còn nếu giả thiết những bệnh nhân có điểm VPS từ 3-5 là có nguy cơ viêm phổi thì chúng tôi thấy trong số 85 bệnh nhân có điểm VPS từ 3-5 chỉ có 23 bệnh nhân bị viêm phổi, độ nhạy để xác định viêm phổi là $27 \%$ (23/85). Như' vậy, áp dụng thang điểm VPS trong nghiên cứu này chúng tôi thấy khả năng dự báo viêm phổi cũng có độ đặc hiệu cao nhưng độ nhạy thấp.

\section{KẾT LUÂ̂N}

Ở bệnh nhân đột quy não giai đoạn cấp, viêm phổi bệnh viện chiếm 13,5\%. Có mối liên quan giữa đột quỵ não thể chảy máu, có thông khí cơ học, tình trạng rối loạn ý thức nặng, mức độ đột quỵ. nặng với tỉ lệ viêm phổi bệnh viện. Thang điểm VPS có khả nắng dự báo viêm phổi với độ đặc hiệu cao $(95,4 \%)$ nhưng độ nhạy thấp (27\%).

\section{TÀI LIẸU THAM KHẢO}

1. Hannawi Y, Hannawi B, Rao CPV et al (2013) "Stroke-associated pneumonia: major advances and obstacles", Cerebrovascular Diseases, 35(5), pp. 430-443.

2. Kwon HM, Jeong SW, Lee SH, Yoon BW (2006), "The pneumonia score: a simple grading scale for prediction of pneumonia after acute stroke", Am J Infect Control, 34(2), pp:64-68.

3. Bộ Y Tế (2012), "Hướng dẫn chẩn đoán và điều trị viêm phổi mắc phải ở bệnh viên, viêm phổi liên quan đến thở máy, viêm phổi liên quan chăm sóc y tế", Hướng dẫn chẩn đoán và điêu trị bệnh hô hấp, Nhà xuất bản $Y$ học, pp: 40-48.

4. Kissela BM, Khoury JC, Alwell K et al (2012), "Age at stroke: temporal trends in stroke incidence in a large, biracial population.", Neurology, 79(17), pp:1781-1787.

5. Appelros P, Stegmayr B, Terént A (2009), "Sex differences in stroke epidemiology: a systematic review", Stroke, 40(4), pp:1082- 1090.

6. Cugy E, Sibon I (2017), "Stroke-Associated 
Pneumonia Risk Score: Validity in a French Stroke Unit.", J Stroke Cerebrovasc Dis, 26(1), pp:225-229.

7. Smith C.J., Kishore A.K., Vail A. et al (2015), "Diagnosis of Stroke-Associated Pneumonia", Stroke, 46(8), p. 2335-2340.

8. Papavasileiou $V$, Milionis $H$, Smith CJ et al
(2015), "External Validation of the Prestroke Independence, Sex, Age, National Institutes of Health Stroke Scale (ISAN) Score for Predicting Stroke-Associated Pneumonia in the Athens Stroke Registry.", J Stroke Cerebrovasc Dis, 24(11), pp:2619-2624.

\section{MỨC Độ SÃ̃N SÀNG CHI TRẢ CHO SÀNG LỌC TRƯỚC SINH HộI CHỨNG DOWN TẠI BỆNH VIỆN PHỤ SẢN HÀ NộI NĂM 2020 \\ Nguyễn Duy Ánh*}

\section{TÓM TẮT}

Mục tiêu: Nghiên cứu nhằm xác định tỷ lệ và mức sẵn sàng chi trả của phụ nữ mang thai cho việc sàng lọc trước sinh hội chứng Down tại bệnh viện Phụ sản Hà Nô̂i năm 2020. Phương pháp: Sử dụng phương pháp lượng giá ngẫu nhiên phụ thuộc với thiết kế cậu hỏi có - không nhằm ước tính tỷ lệ và mức độ sẵn sàng chi trả đối với việc sàng lọc trước sinh hội chứng Down trên 223 phụ nữ mang thai được lựa chọn ngẫu nhiên từ danh sách người bệnh đến khám tại Trung tâm Chẩn đoán trước sinh và sàng lọc sơ sinh Bệnh viện Phụ sản Hà Nội từtháng 3 đến tháng 6 năm 2020. Kết quả và kết luận: Kết quả cho thây $95 \%$ phụ nữ mang thai sẵn sàng chi trả cho biện pháp sàng lọc kết hợp, mức giá trung bình để thai phư sẵn sàng chi trả là 1.905 .010 đồng. Tuy nhiên, chỉ có $65 \%$ thai phụ sẵn sàng chi trả cho xét nghiệm tiền sản không xâm lấn, mức giá trung bình để thai phụ sẵn sàng chi trả là 9.097.230đ̛̂̀ng.

Tư khoá: Sẵn sàng chi trả, sàng loc trước sinh, sàng lọc kết hợp, xét nghiệm tiền sản không xâm lấn, bệnh viện Phụ sản Hà Nội

\section{SUMMARY}

\section{WILLINGNESS TO PAY FOR DOWN} SYNDROME PRENATAL SCREENING OF PREGNANT WOMEN AT HANOI OBSTETRICS

AND GYNECOLOGY HOSPITAL, 2020

Objective: To determine the rate and willingness to pay of pregnant women for Down syndrome prenatal screening at Hanoi Obstetrics and Gynecology Hospital in 2020. Method: Employing contigent valuation method with double-bounded question design to estimate willingness to pay for prenatal screening for Down syndrome with 223 pregnant women randomly selected from the list of patients visiting the Center for Prenatal Diagnosis and Newborn Screening at Hanoi Obstetrics and Gynecology Hospital from March to June, 2020. Results and conclusions: The results showed that $95 \%$ of

*Bệnh viện Phụ sản Hà Nội

Chịu trách nhiệm chính: Nguyễn Duy Ánh

Email: bsanhbnhn@yahoo.com

Ngày nhận bài: 8.4.2021

Ngày phản biên khoa học: 28.5.2021

Ngày duyệt bài: 9.6.2021 pregnant women were willing to pay for combined screening, the average price for which pregnant women were willing to pay was VND 1,905,010. However, only $65 \%$ of pregnant women were willing to pay for a non-invasive prenatal test, the average price for a pregnant woman willing to pay was VND $9,097,230$.

Keywords: willingness to pay, prenatal screening, combined screening, non-invasive prenatal test, Hanoi Obstetrics and Gynecology Hospital

\section{I. ĐĂTT VẤN ĐỀ}

Hội chứng (HC) Down là một trong những bất thường nhiễm sắc thể dễ bi bỏ sót trên siêu âm thai nhi và nhiều nghiên cứu trên thế giới cho thấy nguy cơ thai mắc HC Down tăng theo tuổi mẹ. Theo Tổ chức y tế thế giới (WHO), tỷ lệ mắc HC Down là 1:800 đến 1:1000 trẻ sinh sống. Theo nghiên cứu của Lê Thanh Thúy thực hiện tại Bệnh viện Phụ sản Hà Nội năm 2014, tỷ lệ thai nhi mắc HC Down chiếm 38\% những trường hợp có bất thường nhiễm sắc thể. Một trong những giải pháp để tăng chất lượng dân số, giảm gánh nặng bệnh tật cho gia đình là thực hiện các biện pháp sàng lọc trước sinh. Việc thực hiện các biện pháp sàng lọc sẽ giúp phụ nữ mang thai (PNMT) biết được nguy cơ thai nhi có mắc HC Down hay không, đối với các trường hợp có nguy cơ cao sẽ được tư vấn và chỉ định chọc ối hoặc sinh thiết gai rau để chẩn đoán chính xác tình trạng bất thường nhiễm sắc thể của thai nhi. Tuy nhiên tỷ lệ sảy thai do chọc ối khoảng 1-2\%. Sàng lọc kết hợp trong 3 tháng đâu mang thai (FTS) có tỷ lệ dương tính giả $>5 \%$ và độ chính xác $80-85 \%$. Từ năm 1997, các nhà nghiên cứu trên thế giới đã tìm ra biện pháp xét nghiệm tiền sản không xâm lấn (NIPT) sử dụng ADN tự do của thai nhi có trong máu mẹ để sàng lọc HC Down, xét nghiệm này có độ chính xác cao (>95\%) và tỷ lệ dương tính giả thấp (<1\%).

Khái niệm sẵn sàng chi trả đề cập đến giá trị kinh tế của một người hay một gia đình sẵn sàng chi trả cho một dịch vụ nào đó trong điêu kiện kinh tế cho phép. Sự sẵn sàng chi trả ở đây thực 